\title{
Solubility of Anthracene in Binary Alkane + 1-Propanol and Alkane + 1-Butanol Solvent Mixtures
}

\author{
Anita I. Zvaigzne, I-Lih Teng, Erika Martinez, Jennifer Trejo, and William E. Acree, Jr.* \\ Department of Chemistry, University of North Texas, Denton, Texas 76203-5068
}

\begin{abstract}
Experimental solubilities are reported for anthracene dissolved in 12 binary mixtures containing 1-propanol or 1-butanol with hexane, heptane, octane, cyclohexane, methylcyclohexane, and 2,2,4-trimethylpentane at $25{ }^{\circ} \mathrm{C}$. Results of these measurements are used to test two mathematical representations based upon the combined nearly ideal binary solvent (NIBS)/Redlich-Kister equation and modified Wilson model. For the systems studied, the combined NIBS/Redlich-Kister equation was found to provide the better mathematical representation, with deviations between experimental and back-calculated values being on the order of $\pm 1.5 \%$ or less.
\end{abstract}

\section{Introduction}

Solid-liquid equilibrium data of organic nonelectrolyte systems are becoming increasingly important in the petroleum industry, particularly in light of present trends toward heavier feedstocks and known carcinogenicity/mutagenicity of many of the larger polycyclic aromatic compounds. Solubility data for a number of polycyclic aromatic hydrocarbons (1-5) (i.e., anthracene and pyrene) and heteroatom polynuclear aromatics (6-9) (i.e., carbazole, dibenzothiophene, and xanthene) have been published in the recent chemical literature. Despite efforts by experimentalists and scientific organizations, in terms of both new experimental measurements and criticallyevaluated data compilations, there still exist numerous systems for which actual solubility data are not readily available.

To address this problem, researchers have turned to group contribution methods and semiempirical expressions to predict desired quantities. Group contribution methods have proved fairly successful in estimating solid solubility in pure and binary solvent mixtures from structural information (1017). Practical application though is limited to systems for which all group interaction parameters are known. Generally, interaction parameters are evaluated from solid-liquid and liquid-vapor equilibrium data. It is important that the data base contain as many different functional groups as possible, preferably with adequate representation from both monoand multifunctional solute/solvent molecules to permit evaluation of potential synergistic effects. The data base should contain sufficient experimental values near infinite dilution in the event that one wishes to determine separate interaction parameters for finite concentration and infinite dilution activity coefficient predictions. The UNIFAC model (18) now has two sets of group interaction parameters, with the publication of the infinite dilution values by Bastos et al. (19).

Predictive expressions for solid-liquid equilibria have also been derived from simple thermodynamic mixing models. The nearly ideal binary solvent (NIBS) model (20-22) developed previously provides a relatively simple method for estimating the excess partial molar properties of a solute, $Z_{\mathrm{A}}^{\mathrm{E}}$, at infinite dilution in a binary solvent (components $\mathrm{B}$ and $\mathrm{C}$ )

$$
Z_{\mathrm{A}}^{\mathrm{E}}=f_{\mathrm{B}}^{\circ}\left(Z_{\mathrm{A}}^{\mathrm{E}}\right)_{\mathrm{B}}+f_{\mathrm{C}}{ }^{\circ}\left(Z_{\mathrm{B}}^{\mathrm{E}}\right)_{\mathrm{C}}-\Gamma_{\mathrm{A}}\left(x_{\mathrm{B}}{ }^{\circ} \Gamma_{\mathrm{B}}+x_{\mathrm{C}}{ }^{\circ} \Gamma_{\mathrm{C}}\right)^{-1} Z_{\mathrm{BC}}^{\mathrm{E}}
$$

* To whom correspondence should be addressed.

$$
f_{\mathrm{B}}^{\circ}=1-f_{\mathrm{C}}^{\circ}=x_{\mathrm{B}}{ }^{\circ} \Gamma_{\mathrm{B}} /\left(x_{\mathrm{B}}{ }^{\circ} \Gamma_{\mathrm{B}}+x_{\mathrm{C}}{ }^{\circ} \Gamma_{\mathrm{C}}\right)
$$

in terms of a weighted mole fraction average of solute properties in the two pure solvents, $\left(Z_{\mathrm{A}}^{\mathrm{E}}\right)_{\mathrm{B}}$ and $\left(Z_{\mathrm{A}}^{\mathrm{E}}\right)_{\mathrm{C}}$, and a contribution due to the unmixing of the solvent pair by the presence of the solute. Equation 1 with $Z^{\mathrm{E}}=G^{\mathrm{E}}$ gives accurate predictions for naphthalene, iodine, $p$-dibromobenzene, benzil, $p$-benzoquinone, biphenyl, tolylacetic acid, thianthrene, carbazole, benzoic acid, and phenylacetic acid solubilities in systems of nonspecific physical interactions when molar volumes are used as weighting factors $\left(\Gamma_{i}=V_{i}\right)(9,22-26)$. Approximation of weighting factors with molecular surface areas enables eq 1 to provide accurate predictions for anthracene (1) and pyrene (3) solubilities in binary solvent mixtures containing benzene. More recently $(27,28)$, both the NIBS and modified Wilson (29) models have served as the point of departure for the mathematical representation of solute solubility as a function of solvent composition

$$
\begin{gathered}
\ln x_{\mathrm{A}}^{\mathrm{sat}}=x_{\mathrm{B}}{ }^{\circ} \ln \left(x_{\mathrm{A}}^{\mathrm{sat}}\right)_{\mathrm{B}}+x_{\mathrm{c}}{ }^{\circ} \ln \left(x_{\mathrm{A}}^{\mathrm{sat}}\right)_{\mathrm{C}}+ \\
x_{\mathrm{B}}{ }^{\circ} x_{\mathrm{C}}{ }^{\circ} \sum_{i=0}^{N} S_{i}\left(x_{\mathrm{B}}{ }^{\circ}-x_{\mathrm{C}}{ }^{\circ}\right)^{i} \\
\ln \left(a_{\mathrm{A}}^{\mathrm{solid}} / x_{\mathrm{A}}^{\mathrm{sat}}\right)=1-x_{\mathrm{B}}{ }^{\circ}\left\{1-\ln \left[a_{\mathrm{A}}^{\mathrm{solid}} /\left(x_{\mathrm{A}}^{\mathrm{sat}}\right)_{\mathrm{B}}\right]\right\} /\left(x_{\mathrm{B}}{ }^{\circ}+\right. \\
\left.x_{\mathrm{C}}{ }^{\circ} \Lambda_{\mathrm{BC}}^{\mathrm{adj}}\right)-x_{\mathrm{C}}{ }^{\circ}\left\{1-\ln \left[a_{\mathrm{A}}^{\mathrm{solid}} /\left(x_{\mathrm{A}}^{\mathrm{sat}}\right)_{\mathrm{C}}\right]\right\} /\left(x_{\mathrm{B}}{ }^{\circ} \Lambda_{\mathrm{CB}}^{\mathrm{adj}}+x_{\mathrm{C}}{ }^{\circ}\right)
\end{gathered}
$$

with the various $S_{i}$ and $\Lambda_{i j}^{\text {adj }}$ coefficients computed from measured solubility data via least-squares analysis. The various symbols are defined in the Glossary.

Continued development of solution models for describing the thermodynamic properties of a solute in binary solvent systems requires that a large data base be available for assessing the applications and limitations of derived expressions. Currently, only a limited data base exists for crystalline nonelectrolyte solubility in binary solvent mixtures. For this reason, anthracene solubilities were determined in six alkane +1-propanol and six alkane +1-butanol mixtures. Results of these measurements are used to further test the descriptive abilities of eqs 3 and 4.

\section{Experimental Methods}

Anthracene (Aldrich, 99.9+\%) was used as received. Cyclohexane (Aldrich, HPLC), hexane (Aldrich, $99 \%$ ), heptane (Aldrich, HPLC), octane (Aldrich, 99+\%, anhydrous), methylcyclohexane (Aldrich, 99+\%, anhydrous), and 2,2,4trimethylpentane (Aldrich, HPLC) were stored over molecular sieves to remove trace water shortly before use. 1-Propanol 
Table I. Experimental Mole Fraction Solubilities of Antracene (A) in Binary Alkane + 1-Propanol Solvent Mixtures at $25.0^{\circ} \mathrm{C}$

\begin{tabular}{|c|c|c|c|c|c|}
\hline$x_{c}^{0}$ & $x_{A}^{\text {ant }}$ & $x_{0}{ }^{\circ}$ & $x_{A}^{\text {sat }}$ & $x_{c}^{0}$ & $x_{\mathrm{A}}^{\text {eat }}$ \\
\hline \multicolumn{6}{|c|}{ Hexane (B) + 1-Propanol (C) } \\
\hline 0.0000 & 0.001274 & 0.5447 & 0.001071 & 0.8712 & \\
\hline & 0.001288 & & 0.000990 & & \\
\hline & & & & & \\
\hline \multicolumn{6}{|c|}{ Heptane (B) + 1-Propanol (C) } \\
\hline 0.0000 & 0.001571 & 0.5674 & 0.001182 & 0.8824 & 0.00 \\
\hline 0.1719 & 0.001566 & & & & \\
\hline 0.3272 & 0.001456 & & & 1.0000 & \\
\hline \multicolumn{6}{|c|}{ Octane (B) + 1-Propanol (C) } \\
\hline 0.0000 & 0.001838 & 0.5892 & 0.001300 & 0.8939 & 0.0 \\
\hline & & & & 0.94 & \\
\hline & & & & & \\
\hline \multicolumn{6}{|c|}{ Cyclohexane (B) + 1-Propanol (C) } \\
\hline & 0.001553 & & & & \\
\hline & & & & 0.92 & \\
\hline & & 0.6 & & 1.0000 & \\
\hline \multicolumn{6}{|c|}{ Methylcyclohexane (B) + 1-Propanol (C) } \\
\hline & 0.001649 & 0.5326 & 0.001294 & 0.8687 & 0.00 \\
\hline & 0.00 & 0.6 & 0.00 & 0.9328 & 0.000 \\
\hline & 0.00 & 0.7206 & 01018 & 1.0000 & 0.000591 \\
\hline \multicolumn{6}{|c|}{ 2,2,4-Trimethylpentane (B) + 1-Propanol (C) } \\
\hline 0000 & 0.001074 & 0.5891 & 0.000929 & 0.8968 & 0.000 \\
\hline & 0.001089 & & 0.000862 & & 0.000649 \\
\hline & 0.001057 & 0.7911 & 0.000783 & 1.0000 & 0.000591 \\
\hline
\end{tabular}

(Aldrich, 99+\%, anhydrous) and 1-butanol (Aldrich, HPLC, $99.8+\%)$ were stored over both anhydrous sodium sulfate and molecular sieves before being fractionally distilled. Gas chromatographic analysis showed solvent purities to be $99.7 \%$ or better. Karl Fisher titration gave water contents $(w / w)$ of $<0.003 \%$ and $<0.01 \%$ for 1-propanol and 1-butanol, respectively. Binary solvent mixtures were prepared by weight so that compositions could be calculated to 0.0001 mole fraction.

Excess solute and solvent were placed in amber glass bottles and allowed to equilibrate in a constant-temperature water bath at $25.0 \pm 0.1{ }^{\circ} \mathrm{C}$ for several days. Attainment of equilibrium was verified by repetitive measurements after several additional days and by approaching equilibrium from supersaturation by preequilibrating the solutions at a higher temperature. Aliquots of saturated anthracene solutions were transferred through a coarse filter into a tared volumetric flask to determine the amount of sample and diluted quantitatively with methanol. Concentrations were determined spectrophotometrically at $356 \mathrm{~nm}$ on a Bausch and Lomb Spectronic 2000. Experimental anthracene solubilities in the 12 binary alkane + 1-propanol and alkane +1-butanol mixtures studied are listed in Tables I and II, respectively. Numerical values represent the average of between four and eight independent determinations, with the measured values being reproducible to within $\pm 1 \%$. Experimental anthracene solubilities in the pure alkane solvents are in excellent agreement with published values in the chemical literature (1).

\section{Results and Discussion}

The ability of eqs 3 and 4 to mathematically represent the experimental solubility of anthracene in 12 binary alkane + 1-propanol and alkane +1 -butanol solvent systems is summarized in Table III in the form of "curve-fit" parameters and percent deviations in back-calculated solubilities for the two-parameter expressions. In the case of eq 3 the threeparameter form was also considered. During the course of evaluating parameters for the modified Wilson equation, it was noted on a $\Lambda_{\mathrm{BC}}^{\text {adj }}$ versus $\Lambda_{\mathrm{CB}}^{\text {add }}$ versus percent deviation three-dimensional map there existed several parameter pairs
Table II. Experimental Mole Fraction Solubilities of Anthracene (A) in Binary Alkane + 1-Butanol Solvent Mixtures at $25.0^{\circ} \mathrm{C}$

\begin{tabular}{|c|c|c|c|c|c|}
\hline$x_{c}{ }^{0}$ & $x_{A}^{\text {nat }}$ & $x_{c}^{0}$ & $x_{A}^{\text {ent }}$ & $x_{c}{ }^{0}$ & $x_{\mathbf{A}}^{\text {eat }}$ \\
\hline \multicolumn{6}{|c|}{ Herane (B) + 1-Butanol (C) } \\
\hline 0.0000 & 0.001274 & 0.4876 & 0.001218 & 0.8479 & 0.000931 \\
\hline & & & & & \\
\hline & & 0.6804 & & & \\
\hline \multicolumn{6}{|c|}{ Heptane (B) + 1-Butanol (C) } \\
\hline 0.0000 & 0.001571 & 0.5171 & 0.001333 & 0.8622 & 0.000972 \\
\hline & & 0.6174 & & & \\
\hline & & & & & \\
\hline \multicolumn{6}{|c|}{ Octane (B) + 1-Butanol (C) } \\
\hline 0.0000 & 0.00 & 0.5368 & 0.001467 & & 0.00 \\
\hline 0.1645 & 0.001 & 0.6389 & 0.001 & 0.936 & 0.00 \\
\hline & & 0.7313 & & & \\
\hline \multicolumn{6}{|c|}{ Cyclohexane (B) + 1-Butanol (C) } \\
\hline & 0.001 & 0.4380 & 0.001414 & & 0.00 \\
\hline & 0.001 & 0.5 & 0.001 & & 0.00 \\
\hline & & 0.6811 & & & \\
\hline \multicolumn{6}{|c|}{ Methylcyclohexane (B) + 1-Butanol (C) } \\
\hline 0.0000 & 0.001649 & 0.4783 & 0.001453 & 0.8449 & 0.00 \\
\hline 0.13 & 0.00 & 0.574 & 0.001 & 0.9221 & 0.00 \\
\hline & & 0.676 & 01193 & 1.0000 & 0.000801 \\
\hline \multicolumn{6}{|c|}{ 2,2,4-Trimethylpentane (B) + 1-Butanol (C) } \\
\hline 0.0000 & 0.001074 & 0.5376 & 0.001051 & 0.8819 & 0.000870 \\
\hline 0.1567 & 0.001125 & 0.6387 & 0.000996 & & 0.000838 \\
\hline 0.3031 & 0.001121 & 0.7330 & 1.000800 & 1.0000 & 0.000801 \\
\hline
\end{tabular}

which described the anthracene solubility to within the same level of error. For example, in the case of anthracene solubilities in hexane + 1-butanol mixtures, the percent deviation was approximately $0.4 \%$ for $\Lambda_{\mathrm{BC}}^{\mathrm{ed}}=1.690$ and $\Lambda_{\mathrm{CB}}^{\text {adj }}=1.088,1.2 \%$ for $\Lambda_{\mathrm{BC}}^{\text {adj }}=1.810$ and $\Lambda_{\mathrm{CB}}^{\text {add }}=1.000$, and $1.2 \%$ for $\Lambda_{\mathrm{BC}}^{\mathrm{adj}}=1.400$ and $\Lambda_{\mathrm{CB}}^{\mathrm{adj}}=1.200$. No special attempt was made to optimize calculated $\Lambda_{i j}^{\text {adj }}$ values as we wished only to learn if eq 4 could be used to mathematically represent experimental data in systems covering modest ranges in mole fraction solubilities. Any parameter set having $\pm 1.5 \%$ deviation was sufficient for this purpose.

The numerical value of $a_{A}^{\text {solid }}=0.01049$ (1) used in the modified Wilson computations was calculated from the molar enthalpy of fusion, $\Delta H_{\mathrm{A}}^{\text {fue }}$, at the normal melting point temperature of the solute, $T_{\mathrm{mp}}$ :

$$
\ln a_{\mathrm{A}}^{\text {solid }}=-\Delta H_{\mathrm{A}}^{\text {fus }}\left(T_{\mathrm{mp}}-T\right) /\left(R T T_{\mathrm{mp}}\right)
$$

Attempts to eliminate $a_{A}^{\text {solid }}$ from the mathematical representation in favor of a simplified version $\left(a_{A}^{\text {olid }}=1\right.$ ) proved unsuccessful.

Careful examination of Table III reveals that eq 4 provides fairly reasonable (though by no means perfect) mathematical representations of all 12 systems studied. Back-calculated and experimental values generally differ by less than $\pm 2 \%$, except those for 1-butanol mixtures containing 2,2,4-trimethylpentane and for 1-propanol mixtures containing cyclohexane and methylcyclohexane. These three systems exhibit modest maximum anthracene solubilities near pure alkane, and the "optimum" set of $\Lambda_{i j}^{\text {ddj }}$ values fails to predict the observed solubility maxima. In comparison, the threeparameter mathematical representation based upon the combined NIBS/Redlich-Kister models, eq 3, correctly predicts the solubility maxima and describes the data to within an average absolute deviation of $\pm 0.5 \%$, which is comparable to the experimental uncertainty. There may be one or two individual data points within each system, however, for which the deviations exceed $\pm 2 \%$.

From a computational standpoint, eq 3 will likely be preferred because most research groups involved in reporting 
Table III. Mathematical Representation of Anthracene Solubilities in Several Binary Alkane (B) + 1-Propanol (C) and Alkane (B) + 1-Butanol (C) Solvent Mixtures

\begin{tabular}{|c|c|c|c|c|c|c|}
\hline \multirow[b]{2}{*}{ binary solvent system } & \multicolumn{2}{|c|}{ 2-param eq 3} & \multicolumn{2}{|c|}{ 3-param eq 3} & \multicolumn{2}{|c|}{ eq 4} \\
\hline & $S_{i}^{a}$ & $\% \operatorname{dev}^{b}$ & $S_{i}^{a}$ & $\%$ devb & $\Lambda_{i j}^{\text {adj } c}$ & $\%$ dev $b$ \\
\hline hexane + 1-propanol & $\begin{array}{r}1.033 \\
-0.121\end{array}$ & 0.5 & $\begin{array}{r}0.982 \\
-0.075 \\
0.186\end{array}$ & 0.2 & $\begin{array}{l}1.360 \\
1.440\end{array}$ & 0.5 \\
\hline heptane + 1-propanol & $\begin{array}{r}1.184 \\
-0.182\end{array}$ & 1.0 & $\begin{array}{r}1.098 \\
-0.106 \\
0.324\end{array}$ & 0.4 & $\begin{array}{l}1.410 \\
1.580\end{array}$ & 0.7 \\
\hline octane + 1-propanol & $\begin{array}{r}1.340 \\
-0.361\end{array}$ & 0.9 & $\begin{array}{r}1.275 \\
-0.290 \\
0.250\end{array}$ & 0.3 & $\begin{array}{l}1.240 \\
1.880\end{array}$ & 0.6 \\
\hline cyclohezane + 1-propanol & $\begin{array}{l}1.207 \\
0.015\end{array}$ & 1.0 & $\begin{array}{l}1.121 \\
0.040 \\
0.256\end{array}$ & 0.5 & $\begin{array}{l}1.300 \\
1.600\end{array}$ & 1.6 \\
\hline methylcyclohexane + 1-propanol & $\begin{array}{l}1.291 \\
0.047\end{array}$ & 0.8 & $\begin{array}{l}1.235 \\
0.088 \\
0.204\end{array}$ & 0.5 & $\begin{array}{l}1.344 \\
1.667\end{array}$ & 1.4 \\
\hline 2,2,4-trimethylpentane + 1-propanol & $\begin{array}{r}0.892 \\
-0.192\end{array}$ & 0.9 & $\begin{array}{r}0.825 \\
-0.103 \\
0.291\end{array}$ & 0.4 & $\begin{array}{l}1.100 \\
1.500\end{array}$ & 0.6 \\
\hline hexane + 1-butanol & $\begin{array}{l}0.703 \\
0.183\end{array}$ & 0.5 & $\begin{array}{r}0.737 \\
0.165 \\
-0.124\end{array}$ & 0.4 & $\begin{array}{l}1.690 \\
1.088\end{array}$ & 0.4 \\
\hline heptane + 1-butanol & $\begin{array}{r}0.779 \\
-0.032\end{array}$ & 0.8 & $\begin{array}{l}0.723 \\
0.004 \\
0.201\end{array}$ & 0.2 & $\begin{array}{l}1.476 \\
1.291\end{array}$ & 0.5 \\
\hline octane +1 -butanol & $\begin{array}{r}0.933 \\
-0.033\end{array}$ & 0.6 & $\begin{array}{r}0.909 \\
-0.014 \\
0.088\end{array}$ & 0.4 & $\begin{array}{l}1.460 \\
1.500\end{array}$ & 0.5 \\
\hline cyclohexane + 1-butanol & $\begin{array}{l}0.810 \\
0.336\end{array}$ & 0.9 & $\begin{array}{l}0.741 \\
0.345 \\
0.223\end{array}$ & 0.5 & $\begin{array}{l}2.377 \\
1.010\end{array}$ & 0.5 \\
\hline methylcyclohexane + 1-butanol & $\begin{array}{l}0.948 \\
0.282\end{array}$ & 1.1 & $\begin{array}{l}0.850 \\
0.146 \\
0.295\end{array}$ & 1.0 & $\begin{array}{l}2.387 \\
1.080\end{array}$ & 0.9 \\
\hline 2,2,4-trimethylpentane +1 -butanol & $\begin{array}{l}0.576 \\
0.121\end{array}$ & 0.5 & $\begin{array}{l}0.536 \\
0.151 \\
0.142\end{array}$ & 0.3 & $\begin{array}{l}2.600 \\
0.680\end{array}$ & 1.8 \\
\hline
\end{tabular}

${ }^{a}$ Combined NIBS/Redlich-Kister curve-fit parameters are ordered as $S_{0}, S_{1}$, and $S_{2},{ }^{b}$ Deviation $(\%)=(100 / N) \Sigma\left|\ln \left(x_{\mathrm{A}}^{\text {ealc }} / x_{\mathrm{A}}^{\mathrm{exp}}\right)\right| \cdot{ }^{c}$ Adjustable parameters for the modified Wilson equation are ordered as $\Lambda_{\mathrm{BC}}^{\text {adj }}$ and $\Lambda_{\mathrm{CB}}^{\text {adj }}$.

thermodynamic properties have computer programs for evaluating the Redlich-Kister coefficients. In the case of the two-parameter Redlich-Kister fit, the computations require only a simple linear least-squares analysis of $\left[\ln x_{A}^{\text {sat }}-x_{B}{ }^{0}\right.$ $\left.\ln \left(x_{\mathrm{A}}^{\mathrm{sat}}\right)_{\mathrm{B}}-x_{\mathrm{C}}{ }^{\circ} \ln \left(x_{\mathrm{A}}^{\mathrm{sat}}\right)_{\mathrm{C}}\right] / x_{\mathrm{B}}{ }^{\circ} x_{\mathrm{C}}{ }^{\circ}$ versus $x_{\mathrm{B}}{ }^{\circ}-x_{\mathrm{C}}{ }^{\circ}$. With this idea in mind, we recommend that not only the future presentations of experimental isothermal solubility data for slightly soluble solid solutes dissolved in binary solvent mixtures include a tabulation of the actual observed values but, if possible, that the solubility data be mathematically represented by eq 3 . Realizing that a single equation will not be applicable to all systems encountered, we further suggest eq 4 as an alternative mathematical representation for systems having extremely large solubility ranges and/or highly asymmetrical $\ln x_{\mathrm{A}}^{\text {sat }}$ versus $x_{\mathrm{B}}{ }^{\circ}$ curves, such as the carbazole + alkane + tetrahydropyran systems reported previously (28).

\section{Glossary}

$a_{\mathrm{A}}^{\text {solid }}$ activity of the solid solute, defined as the ratio of the fugacity of the solid to the fugacity of the pure subcooled liquid

$f_{\mathrm{B}}{ }^{\circ}, f_{\mathrm{C}} \mathrm{C}^{\circ} \quad$ weighted mole fraction composition of the binary solvent mixture, calculated as if the solute were not present

$\Delta H_{\mathrm{A}}^{\text {fus }} \quad$ molar enthalpy of fusion of the solute $S_{i} \quad$ adjustable curve-fit parameter in the combined NIBS/Redlich-Kister mathematical representation
$x_{\mathrm{B}}{ }^{\circ}, x_{\mathrm{C}}{ }^{\circ}$ mole fraction composition of the binary solvent mixture, calculated as if the solute were not present

$x_{\mathrm{A}}^{\text {sat }} \quad$ saturated mole fraction solubility of the solute

$\left(x_{\mathrm{A}}^{\mathrm{sat}}\right)_{i} \quad$ saturated mole fraction solubility of the solute in pure solvent component $i$

$Z_{\mathrm{BC}}^{\mathrm{E}} \quad$ excess molar thermodynamic property of the binary solvent mixture at mole fraction composition $x_{\mathrm{B}}{ }^{\circ}$

$\left(Z_{\mathrm{A}}^{\mathrm{E}}\right)_{i} \quad$ excess partial molar property of the solute in pure solvent component $i$

$\Lambda_{i j}^{\text {adj }} \quad$ adjustable curve-fit parameter in the modified Wilson mathematical representation

$\Gamma_{i} \quad$ weighting factor for component $i$

\section{Literature Cited}

(1) Acree, W. E., Jr.; Rytting, J. H. J. Pharm. Sci. 1983, 72, 292.

(2) Judy, C. L.; Pontikos, N. M.; Acree, W. E., Jr. J. Chem. Eng. Data $1987,32,60$

(3) Judy, C. L.; Pontikos, N. M.; Acree, W. E., Jr. Phys. Chem. Liq. $1987,16,179$.

(4) Choi, P. B.; Williams, C. P.; Buehring, K. G.; McLaughlin, E. J. Chem. Eng. Data 1985, 30, 403.

(5) Coon, J. E.; Troth, M.; McLaughlin, E. J. Chem. Eng. Data 1987, $32,233$.

(6) McCargar, J. W.; Acree, W. E., Jr. Phys. Chem. Liq. 1987, 17, 123.

(7) McCargar, J. W.; Acree, W. E., Jr. J. Pharm. Sci. 1987, 76, 572.

(8) Coon, J. E.; Sediawan, W. B.; Auwaerter, J. E.; McLaughlin, E. J. Solution Chem. 1988, 17, 519.

(9) Acree, W. E., Jr. Phys. Chem. Liq. 1990, 22, 157.

(10) Acree, W. E., Jr.; Rytting, J. H. Int. J. Pharm. 1983, 13, 197.

(11) Acree, W. E., Jr. Int. J. Pharm. 1984, $18,47$.

(12) Domanska, U.; Hofman, T. J. Solution Chem. 1985, 14, 531. 
(13) Domanska, U. Fluid Phase Equilib. 1985, 35, 217.

(14) Basu, R. S.; Pham, H.; Wilson, D. P. Int. J. Thermophys. 1986, 7, 319.

(15) Ochsner, A. B.; Solsoloski, T. D. J. Pharm. Sci. 1985, 74, 634.

(16) Carta, R.; Dernini, S. J. Chem. Eng. Data 1983, 28, 328.

(17) Martin, A.; Wu, P. L.; Adjei, A.; Beerbower, A.; Prausnitz, J. M. J. Pharm. Sci. 1981, 70, 1260.

(18) Fredenslund, A.; Jones, R. L.; Prausnitz, J. M. AIChE J. 1975, 21, 1086.

(19) Bastos, J. C.; Soares, M. E.; Medina, A. G. Ind. Eng. Chem. Res. $1988,27,1269$.

(20) Burchfield, T. E.; Bertrand, G. L. J. Solution Chem. 1975, 4, 205.

(21) Acree, W. E., Jr.; Bertrand G. L. J. Phys. Chem. 1977, 81, 1170

(22) Acree, W. E., Jr. Thermodynamic Properties of Nonelectrolyte Solutions; Academic Press, Inc.: Orlando, FL, 1984.

(23) Acree, W. E., Jr. J. Chem. Eng. Data 1985, 30, 70.

(24) Judy, C. L.; Acree, W. E., Jr. Int. J. Pharm. 1985, 27, 39.
(25) Acree, W. E., Jr.; Pontikos, N. M.; Judy, C. L. Int. J. Pharm. 1986, $31,225$.

(26) Acree, W. E., Jr.; Tucker, S. A.; Zvaigzne, A. I. Phys. Chem. Liq. $1990,21,45$.

(27) Acree, W. E., Jr.; Zvaigzne, A. I. Thermochim. Acta 1991, 178, 151.

(28) Acree, W. E., Jr.; McCargar, J. W.; Zvaigzne, A. I.; Teng, I.-L. Phys. Chem. Liq. 1991, 23, 27.

(29) Comer, J. F.; Kopecni, M. M. Anal. Chem. 1990, 62, 991.

Received for review August 3, 1992. Revised February 16, 1993. Accepted March 5, 1993. This research was supported in part by a grant from the National Science Foundation (Grant No. CTS8922485). Erika Martinez and Jennifer Trejo also thank the U.S. Department of Education for support provided to them under the Upward Bound Math and Science Program. 